\title{
Use of Slags in the Production of Portland Cement Clinker
}

\author{
V. Konovalov ${ }^{(凶)}$, A. Fedorov, and A. Goncharov \\ Belgorod State Technological University named after V.G. Shukhov, \\ Belgorod, Russia \\ konovalov52@mail.ru
}

\begin{abstract}
The use of technogenic raw materials as input products in the production of portland cement provides for considerable reduction of energy consumption during clinker burning. The study reveals the mineral formation features caused by the change of the liquid phase composition and crystallization of silicate phases. The use of slags in raw mixes increased the mechanical strength of cements by over $50 \%$.
\end{abstract}

Keywords: Slag $\cdot$ Cement $\cdot$ Clinker phases $\cdot$ Microstructure

\section{Introduction}

Any waste can be considered as secondary material resources, which may be fully or partially (as additives) used in production (Klassen et al. 2003). In terms of their physical and chemical properties, slags are similar to igneous rocks used in the production of construction materials. Being exposed to high-temperature treatment and containing basic calcium silicates, they considerably reduce fuel consumption during clinker burning (Vvedensky 1978; Kopeliovich et al. 1998).

\section{Methods and Approaches}

The study included the methods of chemical analysis of input products and clinkers carried out according to GOST 5382-93. The X-ray phase analysis was performed via the powder diffraction technique using DRON-3 M. The polished sections were studied in reflected light using a universal polarizing microscope NU-2 by Karl Zeiss Jena. The etching of polished sections was carried out via the universal etching agent, i.e. M.I. Strelkov's reagent. The thermal test was carried out using the scanning calorimeter STA 449 F1 Jupiter® by NETZSCH in inert media. Thin slag structures were studied on a scanning electron microscope MIRA3 TESCAN. 


\section{Results and Discussion}

Besides others, the LLC South-Ural Mining and Processing Company utilizes smelter slags as input products. The chemical composition of slags and raw materials given in Table 1 indicates a possibility of replacing the natural constituent, i.e. clay, and slightly reducing the consumption of a carbonate component.

Table 1. Chemical composition of input products, $\%$.

\begin{tabular}{l|c|r|r|r|r|r}
\hline Raw mix components & $\mathrm{CaO}$ & $\mathrm{Al}_{2} \mathrm{O}_{3}$ & $\mathrm{Fe}_{2} \mathrm{O}_{3}$ & $\mathrm{SiO}_{2}$ & $\mathrm{MgO}$ & $\mathrm{PPP}$ \\
\hline Blast furnace slag & 39.70 & 8.80 & 2.09 & 39.08 & 4.08 & 0.17 \\
\hline Open-hearth slag & 32.36 & 3.96 & 21.20 & 19.76 & 11.18 & 3.61 \\
\hline Limestone & 52.12 & 0.24 & 0.18 & 1.53 & 0.48 & 43.11 \\
\hline Clay & 7.57 & 12.8 & 6.32 & 50.45 & 3.97 & 12.80 \\
\hline
\end{tabular}

According to X-ray phase analysis, the phase composition of dump blast furnace nongranulated and granulated slag differs only in the intensity of new crystal growths. The main identifiable minerals include gehlenite, akermanit, quartz and melilite minerals.

The DTA method of a dump blast furnace slag in the range of $600-700{ }^{\circ} \mathrm{C}$ demonstrates a slight vague exo-effect caused by ferrous iron oxidation. The same temperature range indicates the decomposition of a secondary calcium carbonate followed by the insignificant loss of a sample mass. At $840-900{ }^{\circ} \mathrm{C}$ the glass phase is crystallized with further heat release.

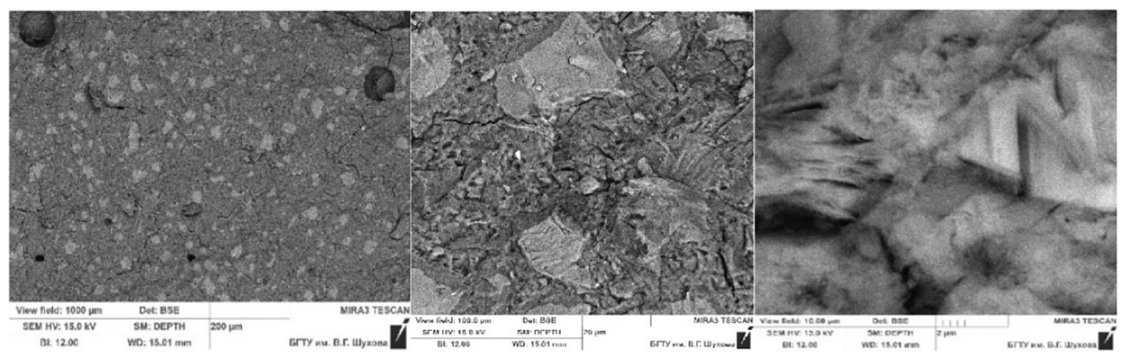

Fig. 1. Microstructure of dump blast furnace slag

The process of devitrification for the blast furnace granulated slag has more expressed exothermic maximum, which is caused by high concentration of a glass phase.

The open-hearth slag acts as a correcting ferrous additive, besides hematite and magnetite is rich in calcium ferrite, monticellite, diopside and magnesium oxide in the form of a periclase.

Figure 1 shows the structure of dump slags representing the conglomerate of crystalline phases and melting particles. The phase formation analysis was carried out in raw mixes having similar chemical composition with various ratio of clay and slag components (Table 2). 
Table 2. Raw mixing ratio

\begin{tabular}{l|l|r|l|l}
\hline Raw mix, No. & Limestone & Clay & Blast furnace slag & Open-hearth slag \\
\hline 1 & $75 \%$ & $22 \%$ & $0 \%$ & $3 \%$ \\
\hline 2 & $61 \%$ & $0 \%$ & $33 \%$ & $6 \%$ \\
\hline
\end{tabular}

The clear exo-effect is observed in a clay-based raw mix (No. 1) at 1227 and $1256{ }^{\circ} \mathrm{C}$ caused by the formation of belite phase, as well as endothermal melting effects at 1288 and $1300{ }^{\circ} \mathrm{C}$. According to (Kougiya, Ugolkov 1981), the exotherm of belite mass crystallization at higher temperatures improves the synthesis of alite and its formation in a fine-crystalline state.

Within sintered materials cooled at $1250{ }^{\circ} \mathrm{C}$ the crystallization of phase C3A and $\mathrm{C} 4 \mathrm{AF}$ is recorded, the reflection intensity of aluminate phase considerably increases with temperature rise. When clay is replaced with slag in a mix the exothermal processes characterizing the formation of silicate phases are weakly expressed within the range of 1000 and $1200{ }^{\circ} \mathrm{C}$. The melting in these mixes is recorded at 1259 and $1308{ }^{\circ} \mathrm{C}$.
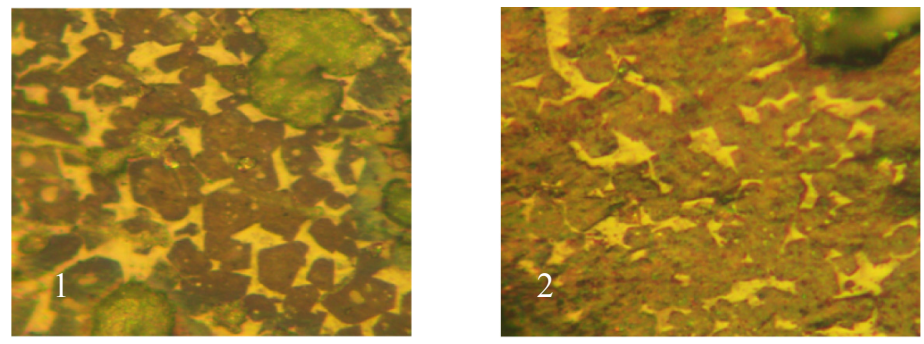

Fig. 2. Micrographs of polished section of sample clinkers: identifications are given in Table 1

Within sintered materials №2 cooled at $1250{ }^{\circ} \mathrm{C}$ the aluminate phase prevails thus leading to the appearance of ferrous phases $-\mathrm{C} 6 \mathrm{~A} 2 \mathrm{~F}$ and $\mathrm{C} 4 \mathrm{AF}$ with temperature rise. The basic clinker fusion is formed at $1327^{\circ} \mathrm{C}$. These differences in A-F formation are clear with the increase of slag concentration in raw mixes. The gehlenite and mayenite is observed at $1200{ }^{\circ} \mathrm{C}$ in clay-containing mixes along with belite phase, which is not observed in slag-containing samples. The introduction of slag intensifies the formation of belite phase at early burning stages. Some changes in the composition of a 'liquid' phase, which increase its temperature and molten viscosity with the increase of slag composition in a raw mix, also affect the features of crystallization of clinker phases.

Figure 2 shows micrographs of polished sections of sample clinkers, which demonstrates the crystallization difference of alite phase.

Clinkers from clay-based raw mixes have clear monadoblastic texture. Clinkers from slag-based raw mixes are different in terms of the number of alite growths.

The strength of cements was defined in small samples from cement paste (1:0) with water-cement ratio of 0.28 . The results given in Table 3 show that the use of slags in raw materials instead of clay positively affects the activity of clinkers. The strength improvement within a 28-day interval at full replacement of a clay component with slag made $62 \%$. The heat burning input of limestone-slag mixes may be reduced by over $0.85 \mathrm{~mJ} / \mathrm{t}$. 
Table 3. Cement stone strength, $\mathrm{W} / \mathrm{C}=0.28$

\begin{tabular}{l|c|l|l}
\hline \multirow{2}{*}{$\begin{array}{l}\text { Mix No., Identifications } \\
\text { are given in Table 1 }\end{array}$} & \multicolumn{3}{|c}{ Tensile strength, } \\
\cline { 2 - 4 } & 2 & 7 & 28 \\
\hline 1 & 7 & 14 & 32 \\
\hline 2 & 30 & 37 & 52 \\
\hline
\end{tabular}

\section{Conclusions}

The integral analysis of raw materials and calcined products indicates the possibility of full replacement of clay in a raw mix for the production of portland cement clinker. This contributes to the improvement of qualitative parameters of a calcined product and to the reduction of its production cost.

Acknowledgements. The study is implemented in the framework of the Flagship University Development Program at Belgorod State Technological University named after V.G. Shukhov, using equipment of High Technology Center at BSTU named after V.G. Shukhov.

\section{References}

Klassen VK, Borisov IN, Klassen AN, Manuylov VE (2003) Features of mineral formation in slag-containing raw mixes of various basicity. Bull High Educ Inst Constr Ser 7:56-58

Kopeliovich VM, Zdorov AI, Zlatkovsky AB (1998) Utilization of industrial wastes in cement production. Cement 3:174

Kougiya MV, Ugolkov VL (1981) Differential thermal analysis of portland cement raw mixes. Cement 11:19-21

Vvedensky VG (1978) Environmental and economic efficiency of waste utilization. Complex Use Mineral Raw Mater 3:59

Open Access This chapter is licensed under the terms of the Creative Commons Attribution 4.0 International License (http://creativecommons.org/licenses/by/4.0/), which permits use, sharing, adaptation, distribution and reproduction in any medium or format, as long as you give appropriate credit to the original author(s) and the source, provide a link to the Creative Commons license and indicate if changes were made.

The images or other third party material in this chapter are included in the chapter's Creative Commons license, unless indicated otherwise in a credit line to the material. If material is not included in the chapter's Creative Commons license and your intended use is not permitted by statutory regulation or exceeds the permitted use, you will need to obtain permission directly from the copyright holder.

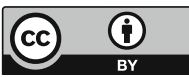

